\title{
Low dose spinal anaesthesia and transversus abdominis plane block in a parturient with peripartum cardiomyopathy for caesarean section following a bloody epidural tap
}

\author{
Nita Varghese ${ }^{1 *}$, Lokvendra Budania ${ }^{2}$, Madhu Rao ${ }^{1}$, Yogesh Gaude ${ }^{2}$, Anupam Berwal ${ }^{3}$ \\ Assistant Professor of Anaesthesiology ${ }^{1 *}$, Associate Professor of Anaesthesiology ${ }^{2}$, Assistant \\ Professor of Microbiology ${ }^{3}$, Kasturba Medical College, Manipal, India.
}

\begin{abstract}
Peripartum cardiomyopathy (PPCM) is a form of dilated cardiomyopathy which presents unique challenges for anaesthetic management. Here we present a case of PPCM who was given low dose spinal anaesthesia with TAP block for caesarean section which is rarely reported. A 33-year-old multigravida, 35 weeks gestation presented with PPCM with ejection fraction of $24 \%$. Elective caesarean section was planned in view of worsening dyspnoea despite treatment. Graded epidural anaesthesia with invasive monitoring was planned but we encountered a bloody tap whilst securing the epidural catheter, hence switched to low dose spinal anaesthesia ( $6 \mathrm{mg}$ of $0.5 \%$ bupivacaine $+10 \mathrm{mcg}$ of fentanyl). Ultrasound guided bilateral TAP block was given for post-operative analgesia. We observed that the patient had a comfortable and haemodynamically stable experience intra and post operatively. Hence a low dose spinal anaesthesia and TAP block with invasive monitoring can be opted as an anaesthetic technique in PPCM.
\end{abstract}

Keywords: Cardiomyopathy; dilated; anaesthesia; spinal; pain; postoperative; nerve block

\section{Introduction}

Anaesthetic goal of maintaining optimal ventricular preload and afterload while avoiding anaesthesia induced vasodilatation and myocardial depression makes peripartum cardiomyopathy (PPCM) challenging for anaesthesiologists. Literature search of anaesthetic management of these patients undergoing operative delivery reveals both general and regional anaesthesia being used with comparable outcomes. ${ }^{1}$ Among the techniques of regional anaesthesia, combined spinal epidural (CSE), continuous spinal anaesthesia and continuous epidural anaesthesia are described in the literature but not single shot spinal anesthesia. ${ }^{2}$ Here we report a case of PPCM who underwent caesarean section (CS) under single shot low-dose spinal anaesthesia and transversus abdominis plane (TAP) block following a failed epidural catheter insertion.

*Correspondence: Nita Varghese

E mail: nitavarghese@gmail.com

http://www.orcid.org/0000-0003-2108-8673

Received: 28/07/2018

Accepted:24/10/2018

DOI: http://doi.org/10.4038/slja.v27i1.8365

\section{Case History}

A 33-year-old multigravida at 35weeks of gestation, apparently normal two months back came with a complaint of increased fatiguability and worsening dyspnoea for three days. Peripartum dilated cardiomyopathy was diagnosed following echocardiography which showed globally hypokinetic left ventricle, severe left ventricular systolic dysfunction with an ejection fraction of $24 \%$, severe mitral regurgitation, moderate to severe pulmonary artery hypertension and moderate tricuspid regurgitation. She gave a history of undergoing CS twice before but had no history of any cardiac disease in the past. On examination, she had a pulse rate of 140 beats/min and blood pressure $110 / 70 \mathrm{mmHg}$ with occasional crepitations in the lungs. ECG showed tachycardia with multiple ventricular premature contractions. She was started on oral carvedilol $12.5 \mathrm{mg} \mathrm{BD}$, oral digoxin $0.25 \mathrm{mg}$ QID and furosemide $40 \mathrm{mg}$ BD to improve her cardiac function. Since there was worsening of dyspnoea despite the treatment she was scheduled for elective CS. After taking informed consent from the patient and relatives she was shifted to the operating room (OR) in semi-reclining position with oxygen via venturimask (40\%). Her baseline pulse rate was 120 beats/min and regular, non-invasive blood pressure $110 / 70 \mathrm{mmHg}$ and oxygen saturation 
$96 \%$. A radial arterial line and right internal jugular central line were secured and emergency drugs, difficult airway cart and defibrillator were kept ready in the OR. Patient was co-loaded with ringer lactate through central line. Our plan was epidural anaesthesia in the sitting position and first attempt at epidural catheterization was done at L3-4. Though the entry at this level was smooth we experienced a bloody tap on catherization and subsequently this happened twice. A change of hands as well as level of epidural space was decided but these attempts at L2-3 and L4-5 also resulted in a bloody tap. Hence, we decided on a low dose spinal anaesthesia. This was achieved with $6 \mathrm{mg}$ of $0.5 \%$ bupivacaine (heavy) and $10 \mu \mathrm{g}$ of fentanyl at L3-4 interspace and patient was made to lie down supine. The level of anaesthesia at one minute was $\mathrm{T} 6$ and patient was comfortable in the lying down position. Haemodynamically she was stable throughout the surgery expect for an initial BP drop to $90 / 45 \mathrm{mmHg}$ that picked up with $250 \mathrm{ml}$ fluid bolus and no inotropic support. A healthy baby was delivered, and the surgery took about 90 minutes during which the patient was comfortable. We then gave bilateral TAP blocks with $20 \mathrm{ml}$ of $0.25 \%$ levo-bupivacaine on each side under ultrasound guidance. Even though her cardiac function and ejection fraction did not improve drastically she was symptomatically better and hence after a period of 7 days she was discharged with advice to continue oral carvedilol, furosemide and warfarin and was asked to review after a month.

\section{Discussion}

The Heart failure Association of the European Society of Cardiology working group have defined PPCM as "an idiopathic cardiomyopathy presenting with heart failure secondary to left ventricular systolic dysfunction towards the end of pregnancy or in the months following delivery where no other cause of heart failure is found. It is a diagnosis of exclusion. The left ventricle may not be dilated but the ejection fraction is nearly always reduced below 45\%. ${ }^{3}$ Even though there is a lack of registry to document such cases in India, Pandit et al have reported an incidence of 1 in 1374 live births from a tertiary referral hospital in South India. ${ }^{1}$

Low cardiac output causes tachycardia, which may gradually progress to dyspnoea, ascites, peripheral oedema, atypical chest pain, embolic phenomena and haemoptysis. Over diagnosis or disregarding of heart disease can happen as symptoms similar to cardiac failure may occur even in normal pregnancy due to normal physiological changes of pregnancy. ${ }^{1}$

Favourable maternal and foetal outcome require that the haemodynamic goals be prioritized while choosing the techniques and drugs to provide anaesthesia. Considering the pathophysiology of PPCM, focus should be on avoiding tachycardia, maintaining adequate preload and avoiding factors that would increase the afterload such as hypoxia, hypercarbia and acidosis. Control of airway and ventilation is better with general anaesthesia (GA), but afterload can increase by sympathetic stimulation during rapid sequence induction and intubation. Inhalation or intravenous induction agents are cardiac depressants but when high dose opioid anaesthesia is used to avoid myocardial depression, it can cause neonatal respiratory depression. ${ }^{4}$ Thromboembolism leading to cardiac failure and even cardiac arrest is seen with GA. ${ }^{5}$ Regional anaesthesia remains the method of choice as the sympathectomy associated with it causes a decrease in cardiac preload and afterload which is beneficial in patients with PPCM. ${ }^{4,5}$ Prevention of thromboembolic events and reduced catecholamines are additional benefits of neuraxial blockade. However, caution must be taken to prevent abrupt fall in BP. ${ }^{6,7}$ Literature reveals that regional anaesthesia was used in patients undergoing non-emergent $\mathrm{CS}$ with relatively stable haemodynamics, while moderately symptomatic patients or those undergoing emergency surgery received general anaesthesia. ${ }^{1} \mathrm{We}$ planned for epidural anaesthesia with invasive haemodynamic monitoring but abandoned it in view of repeated bloody taps during epidural catheter insertion and switched to spinal anaesthesia. Low dose spinal anaesthesia with local anaesthetic and opioid, which is known to minimize haemodynamic instability was chosen. ${ }^{8,9}$ Gupta et al used low dose spinal anaesthesia (5mg bupivacaine $+25 \mathrm{mcg}$ fentanyl) in PPCM patient (EF-25\%) for medical termination of pregnancy and sterilization. ${ }^{6}$ Although anaesthesiologists are apprehensive, there are case reports where low dose spinal block has been successful as the duration of surgery is less. ${ }^{5}$ In our case gradual and restricted coloading prevented acute fall in BP. Though early use of inotropes and inodilators is warranted in PPCM patient we managed the initial fall in BP with fluid bolus without need of vasopressor. 
Sympatholysis induced vasodilatation accommodates extra volume released from uterine contraction, reducing the risk of volume overload due to uterine auto-transfusion. ${ }^{5}$ USG guided bilateral TAP block was given for postoperative analgesia to avoid increased sympathetic activity and cardiac load secondary to pain. ${ }^{10}$

Hence, we conclude that low dose spinal anaesthesia using opioid is an acceptable option for CS in a patient with PPCM.

\section{References}

1. Ramachandran R, Rewari V, Trikha A. Anaesthetic management of patients with peripartum cardiomyopathy. J Obstet Anaesth Crit Care 2011;1:5-12.

http://www.joacc.com/text.asp?2011/1/1/5/842 49; DOI: $10.4103 / 2249-4472.84249$

2. Soni B, Gautam PL, Grewal A, Kaur H. Anaesthetic management of two cases o peripartum cardiomyopathy. J

Obstet Anaesth Crit Care 2011;1:41-5. http://www.joacc.com/text.asp?2011/1/1/41/84 256; DOI: 10.4103/2249-4472.84256.

3. Sliwa K, Hilfiker - Kleiner D, Petrie MC, Mebazaa A, Pieske B, Buchmann E, et al. Current state of knowledge on aetiology, diagnosis, management, and therapy of peripartum cardiomyopathy: A position statement from the Heart Failure Association of the European Society of Cardiology Working Group on peripartum cardiomyopathy. EurJHeartFail2010;12:767-78

https://doi.org/10.1093/eurjhf/hfq120

PMid:20675664

4. McCarroll CP, Paxton LD Elliott P, Wilson DB. Use of remifentanil in a patient with peripartum cardiomyopathy requiring caesarean section. $\mathrm{Br}$ JAnaesth2001;86:135-38. https://doi.org/10.1093/bja/86.1.135 PMid:11575392

5. Wake K, Takanishi T, Kitajima T, Hayashi K, Takahashi H, Sakio H. Cardiac arrest during emergency caesarean section due to peripartum cardiomyopathy. Masui 2003;52:1089-91. PMid:14598674

6. Gupta K, Gupta SP, Jose S, Balachander H. Low dose spinal anaesthesia for peripartum cardiomyopathy. J AnaesthesiolClinPharmacol 2011;27:567-8

https://doi.org/10.4103/0970-9185.86615 PMid:22096304 PMCid:PMC3214576

7. Pirlet M, Baird M, Pryn S, Jones-Ritson M, Kinsella SM. Low dose combine spinal epidural anaesthesia for cesarean section in a patient with peripartum cardiomyopathy.
IntJObstetAnaesth2000;9:189-92. https://doi.org/10.1054/ijoa.1999.0374 PMid:15321091

8. Singh T, Taxak S, Hasija N, Anand A. Anaesthetic management of a parturient with dilated cardiomyopathy: A case report. Egypt J Anaesth 2014;30:439-41. https://doi.org/10.1016/j.egja.2014.03.010

9. Lakshmanan G, Naithani U, Verma D. Low dose spinal anesthesia for emergency cesarean section in a parturient with peripartum cardiomyopathy: a case report. Int J Recent Sci Res 2016;7:10824-6. http://www.recentscientific.com

10. Srivastava U, Verma S, Singh TK, Gupta A, Saxsena A, Jagar KD, Gupta M. Efficacy of trans abdominis plane block for post cesarean delivery analgesia: A double-blind, randomized trial. Saudi J Anaesth 2015;9:298-302. https://doi.org/10.4103/1658-354X.154732 PMid:26240550 PMCid:PMC4478824 